\title{
Viabilidad del Stare Decisis en el Arbitraje Nacional ecuatoriano: Navegando entre puntos conciliables
}

\author{
Gabriel Eduardo Almeida Vintimilla*1 \\ Recibido/Received: 21/06/2021 \\ Aceptado/Accepted: 05/10/2021
}

Sumario: 1. Introducción. 2. El stare decisis. Origen y definición. 2.1. El stare decisis en su sistema originario de Common Law. Conceptos y definiciones fundamentales. 2.2. El stare decisis en los sistemas de Civil Law, ¿inexistente o de desarrollo evolutivo? 3. Relación posible entre stare decisis y la naturaleza jurídica del arbitraje nacional ecuatoriano. 3.1. ¿Existe el stare decisis en el Ecuador? Una concepción escalonada. 3.2. ¿Existe una relación posible y conciliable entre la naturaleza jurídica del arbitraje en el Ecuador y el stare decisis? 3.3. ¿El laudo arbitral en el Ecuador resulta conciliable como elemento que coadyuve a la viabilidad del stare decisis en el sistema arbitral ecuatoriano? 4. ¿Es verificable la aplicación del stare decisis en la práctica jurisprudencial del arbitraje internacional de inversiones? ¿Puntos conciliables con el sistema arbitral ecuatoriano? 4.1. ¿Es asimismo verificable el stare decisis en el arbitraje comercial internacional? ¿Existen puntos conciliables con el sistema arbitral ecuatoriano? 5. ¿La práctica de la Corte Internacional de Justicia verifica la aplicación del stare decisis? ¿Qué puntos conciliables existen con el sistema arbitral ecuatoriano?

* Abogado por la Universidad San Francisco de Quito. Previo a su título de abogado, fue Secretario General de la Sociedad de Estudiantes de Jurisprudencia de la Universidad San Francisco de Quito y finalista del Concurso de Litigio Constitucional organizado por la Pontificia Universidad Católica del Ecuador en 2017. Actualmente maestrante de la Maestría en Litigio y Arbitraje Internacional en la Universidad San Francisco de Quito. Correo electrónico: gabriel. almeida2695@gmail.com

1. El autor desea expresar su más sincero agradecimiento al Dr. Francisco Larrea Naranjo, colega y maestro de la Universidad San Francisco de Quito, guía, apoyo y confianza inigualable e invaluable en el desarrollo del presente trabajo. 
6. ¿Es viable incorporar el stare decisis en el arbitraje nacional ecuatoriano a partir de los puntos conciliables analizados? Propuesta de reforma de la LAM para el arbitraje en Derecho. 7. Conclusiones.

Resumen: El presente artículo busca encontrar la viabilidad de la doctrina stare decisis hacia una jurisprudencia arbitral para el sistema ecuatoriano. En primer lugar analizará su origen, desarrollo y tratamiento jurídico dentro del Common Law, así como dentro del Civil Law. Posteriormente abordará la naturaleza jurídica del arbitraje en el Ecuador, para determinar la existencia de una posible relación entre la doctrina del stare decisis y el derecho arbitral ecuatoriano, sustentando dicha propuesta sobre puntos conciliables verificables en sistemas arbitrales comparados, y unificando dichos puntos conciliables con las características del sistema arbitral ecuatoriano, evidenciando una clara viabilidad y necesidad de su consideración e incorporación, frente a una incipiente existencia de dicha doctrina en el sistema ecuatoriano de justicia. Finalmente, para completar el presente trabajo, se propondrá una reforma a la Ley de Arbitraje y Mediación, agregando un formato de convenio arbitral susceptible de favorecer la inclusión del stare decisis en el arbitraje ecuatoriano, con características y propiedades que le sean adecuadas y a la medida para su procedencia.

Palabras Clave: Stare decisis, puntos conciliables, arbitraje ecuatoriano, jurisprudencia arbitral, viabilidad, precedente.

\section{Viability of Stare Decisis in Ecuadorian domestic Arbitration: Navigating between conciliable points}

Aвstract: This article seeks to find de viability of the stare decisis doctrine, towards an arbitration jurisprudence for the Ecuadorian system. In the first place, it will analyze its origin, development, and legal treatment within Common Law, as well as within Civil Law. Subsequently, it will address the legal nature of arbitration in Ecuador, to determine the existence of a possible relationship between the doctrine of stare decisis and Ecuadorian arbitration law, supporting said proposal on verifiable reconcilable points in compared 
arbitration systems, and unifying said reconcilable points with the characteristics of the Ecuadorian arbitration system, evidencing a clear viability and need for its consideration and incorporation, in comparison with its incipient existence in the Ecuadorian justice administration system. Finally, to complete this work, a reform to the Arbitration and Mediation Law will be proposed, adding an arbitration agreement format likely to favor the inclusion of stare decisis in Ecuadorian arbitration, with characteristics that are appropriate and tailored to its provenance.

Keywords: Stare decisis, reconcilable points, Ecuadorian arbitration, arbitration jurisprudence, viability, precedent.

\section{INTRODUCCIÓN}

La idea de una jurisprudencia arbitral ha sido un tema recurrente en el debate doctrinario relativo a este método alternativo de solución de conflictos. Ciertamente, el concepto de jurisprudencia tradicionalmente conocido representa una serie de impedimentos formales y materiales que resultan irreconciliables con el sistema arbitral. Sin embargo, la institución jurídica del stare decisis, permitiría la consolidación de una jurisprudencia arbitral, en un contexto propio, adaptable y autónomo para dicho sistema.

La doctrina del stare decisis, establece un régimen unificador e integrador de decisiones emitidas por tribunales en casos anteriores sobre la base fundamental de sus rationes decidendi, posteriormente aplicables en el dictamen de un nuevo fallo, sin embargo, requiere como se ha dicho, encontrar puntos conciliables que permitan su adaptabilidad al sistema arbitral ecuatoriano, en contraste con las dificultades que enfrenta dicha doctrina en la justicia ordinaria nacional y que, bien miradas representarán una ventaja inigualable para el sistema arbitral ecuatoriano.

El objeto del presente artículo nace del análisis de la práctica verificable de diversos sistemas de resolución de controversias, cuya jurisdicción emana de la voluntad de las partes protagonistas de determinado conflicto, en donde efectivamente el recurso al stare decisis, para la resolución de nuevos casos -y en consecuencia la 
consolidación y desarrollo de determinados puntos sobre cuestiones jurídicas específicas-, ha tenido un papel primordial.

Resulta que dichos sistemas comparten particulares elementos en común respecto de la aplicación del stare decisis, en casos análogos y similares, tales como: i) publicidad del proceso y de la resolución final; ii) sometimiento voluntario a la jurisdicción de un tercero fuera de la órbita judicial ordinaria; iii) inexistencia de declaración convencional de confidencialidad procesal; iv) designación convencional, de que la decisión emitida dentro de un caso sea publicada, analizada y sistematizada para su posterior incorporación a casos futuros, o su análisis en revistas y artículos de interés jurídico.

De la revisión de la Ley de Arbitraje y Mediación del Ecuador, se desprende que dichos puntos comunes, son igualmente conciliables con las características del sistema arbitral ecuatoriano, de manera que desde una perspectiva crítica, el presente artículo determinará ciertas cuestiones que antaño se consideraron omisiones o inconsistencias incorporadas por parte del legislador ecuatoriano para el sistema arbitral, pero que más bien, visto desde una perspectiva creativa e integradora, pueden constituir el punto de partida para una jurisprudencia arbitral propia, adaptable y autónoma para el sistema arbitral ecuatoriano.

Finalmente, el presente artículo demostrará que, navegando entre puntos conciliables, la viabilidad de la doctrina del stare decisis no solo es posible, sino que también es necesaria para el sistema arbitral ecuatoriano, pues cabe preguntarnos ¿si se verifica su aplicación en sistemas de resolución de disputas comparados, que comparten dichos elementos justificantes de su procedencia, con el sistema arbitral ecuatoriano, existiría impedimento para su incorporación?

\section{EL STARE DECISIS. ORIGEN Y DEFINICIÓN}

\subsection{El stare decisis en su sistema originario de Common Law. Conceptos y definiciones fundamentales.}

El stare decisis -o sistema del precedente- constituye, en su sistema originario de Common Law, una fuente principal del Derecho 
caracterizada por vincular a los tribunales judiciales a la decisión de un tribunal anterior sobre una cuestión de derecho específica. Dicha decisión anterior opera entonces, como una norma de corte legislativo, esencialmente obligatoria para su consideración en decisiones sucesivas en casos futuros y análogos². Esto implica la formación de una tendencia jurisprudencial continuada, pero que determina a su vez, un conjunto de normas, excepciones, principios y limitaciones que ofrecen al juez posterior una orientación sobre la forma de proceder en determinado caso $^{3}$.

Ahora bien, para determinar la vinculatoriedad del precedente, es necesario reconocer dos elementos en la sentencia que lo contiene. El primero, de naturaleza material, corresponde a la sección del fallo que tiene fuerza obligatoria, esto es la ratio decidendi, pues aquella posee la aptitud verdaderamente vinculante, toda vez que materializa el proceso de razonamiento y argumentación jurídica que llevó al tribunal anterior a tal decisión, a diferencia, de la sección obiter dicta, que no es vinculante ni obligatoria, aunque se le reconoce cierta fuerza persuasiva ${ }^{4}$. El segundo elemento, de naturaleza formal, establece que dicho precedente debe haber sido emitido por un tribunal anterior de igual o superior jerarquía, con respecto al tribunal que conoce actualmente o que conocerá y resolverá en el futuro determinado caso ${ }^{5}$.

En tal virtud, resulta obligatorio para los jueces fundamentar sus resoluciones basándose en las rationes decidendi, de decisiones anteriores, identificando las formulaciones o proposiciones de Derecho obtenidas por parte de un tribunal anterior de igual o superior jerarquía, para determinar la regla de derecho aplicable $y$, sin la cual dicho precedente hubiera contenido una decisión diferente ${ }^{6}$.

En este sentido, la obligatoriedad del precedente, en el derecho anglosajón, se extiende en dos ámbitos: horizontal y vertical. El

2. V. ItURRALde. "Precedente Judicial", Revista en Cultura de la Legalidad. Biblioteca Universidad Carlos III de Madrid, 2014, p. 194.

3. S. Whitaker. "El Precedente en el Derecho Inglés: Una Visión desde la Ciudadela", Revista Chilena de Derecho, Vol. 35, 2008, p. 48.

4. Ídem, p. 49.

5. J. WALKer. "The Role of Precedent in the United States: How Do Precedents Lose Their Binding Effect?", Stanford Law School. China Guiding Cases Project, California, 2016. <https:// stanford.io/3hqT5ys $>$, (09/03/2021).

6. R. Cross y J. Harris. El Precedente en el Derecho Inglés. Madrid, Editorial Marcial Pons, 2012, pp. 148-152. 
primero corresponde a la obligación de los tribunales de resolver según lo decidido en casos análogos anteriores por tribunales de la misma jerarquía, mientras que el segundo corresponde al deber de seguir el precedente de sus superiores jerárquicos ${ }^{7}$.

Sin embargo, dentro de esta sistematización anglosajona del stare decisis, puede encontrarse una excepción a su carácter obligatorio a través de dos métodos que permiten apartarse del precedente establecido, dado que su aplicación no es ilimitada. Por un lado, se reconoce la figura del distinguishing, cuando en el análisis de un caso no se verifica la suficiente similitud con uno anterior y por tanto, presenta elementos relevantes distintos. En este caso, el precedente dejará de aplicarse al constatarse dicha ausencia de similitud casuística ${ }^{8}$. Por otro lado, se reconoce la figura del overruling, por medio de la cual se deja sin efecto un precedente para casos futuros, lo que, según Lagarre y Rivera, equivale a una derogación judicial'.

En consecuencia, los aspectos conceptuales del stare decisis en su originario sistema de Common Law, se concretan de la siguiente manera: i) decisión anterior y vinculante para su consideración e incorporación en casos futuros y similares (análogos); ii) en virtud de su naturaleza jurídica, constituye una fuente formal del Derecho anglosajón; iii) establece obligatoriedad de aplicar la ratio decidendi contenida en decisiones anteriores; iv) dicha obligatoriedad tiene aplicación horizontal y vertical en función del tribunal que incorpora esa ratio decidendi a su resolución y; v) existen dos figuras jurídicas que permiten apartarse del precedente y constituyen una excepción a su obligatoriedad: el distinguishing y el overruling.

\subsection{El stare decisis en los sistemas de Civil Law, ¿inexistente o desarrollado progresivamente?}

Dentro de los sistemas que han seguido la tradición jurídica del Civil Law, la doctrina del stare decisis tuvo una aparición tenue en su origen, sin embargo, ha ido consolidándose a través de los años

7. S. Lagarre y J. Rivera. "Naturaleza y Dimensiones del 'Stare Decisis", Revista Chilena de Derecho, Vol. 33, 2006, p. 112.

8. Ídem, p. 114.

9. Ídem, p. 115. 
a través de una paulatina incorporación, tomando como punto de partida, la conceptualización de su símil anglosajón.

Originariamente, su utilidad fue meramente auxiliar, los jueces lo utilizaban para determinar la resolución de un caso concreto cuando se encontraban ante una laguna o vacío normativo únicamente. La labor interpretativa de los juristas tuvo entonces, un papel preponderantemente integrador, pues esencialmente, carecía del carácter obligatorio propio del sistema anglosajón ${ }^{10}$.

Así resalta Eizaguirre cuando señala: “(...) los Tribunales no se hallan vinculados al precedente, según nuestra concepción del Derecho, de la misma forma que a una ley. No es el precedente como tal el que vincula, sino solamente la norma, concretizada y correctamente interpretada por aquel"11.

En adición a lo anterior, de acuerdo con Stürner, constituye un lugar común que la determinación atribuida al precedente bajo este paradigma, nace de la concepción rígida del Derecho Romano basado en la supuesta seguridad de la codificación, para determinar normas jurídicas de manera general y abstracta, cuya finalidad era establecer un sistema normativo capaz de tener solución para cualquier controversia o cuestión jurídica que exista ${ }^{12}$. Sin embargo, esa concepción decimonónica y anacrónica del Derecho continental no siempre se mantuvo así.

Como señala Taruffo, la teoría de que el juez no crea Derecho o debe abstenerse de crearlo, porque la ley podía prever todas o la mayoría de las consecuencias de los actos de las personas en sus relaciones jurídicas, encontró su fin a finales del siglo XIX, siendo sustituida por un naciente paradigma en donde los jueces deben gozar y ejercer la posibilidad de analizar y decidir de manera autónoma e independiente cada caso de acuerdo con las particularidades del mismo ${ }^{13}$.

10. V. ItURRALDE. N. 2.

11. J. M. Eizaguirre. "Civil Law: La vigencia de una categoría convencional", Anuario de Derecho Civil, Madrid, 2012, p. 543. <https://bit.ly/3EbB94F>, (10/03/2021).

12. M. STÜNER. "Tendiendo un puente entre el Common Law y el Derecho Continental. ¿Constituyen las diferentes metodologías de trabajo un obstáculo contra una mayor armonización del Derecho Privado Europeo?”, Revista Jurídica Universidad Autónoma de Madrid, No. 15, 2007, p. 180.

13. M. Taruffo. "Precedente y Jurisprudencia”, Precedente, Anuario Jurídico, p. 87. <https://bit. ly/3AaQ4JV>, (11/03/2021). 
Según Cano, es en esta transformación histórica-jurídica, donde se encuentra el nacimiento y la posterior consolidación del stare decisis, para el Derecho continental, pues en algunas decisiones los jueces podían llegar a tener una función creadora del derecho, en similar sentido a la función que realiza el poder legislativo del Estado, reconociéndoles obligatoriedad y vinculatoriedad, momento desde el cual comienza a determinarse una más estrecha y casi inobservable línea divisoria, con su par en el Common Law ${ }^{14}$. Al respecto, Gascón manifiesta lo siguiente:

No puede sostenerse, a menos que consideremos una visión simplista o ficticia del papel de los procesos judiciales, que en los sistemas del Civil Law la jurisprudencia no tiene ningún valor vinculante; como tampoco se puede decir que en los sistemas del Common Law, el derecho legislado tiene un papel de menor relevancia que el precedente ${ }^{15}$.

Iturralde así lo confirma, pues es verificable como un número importante de países de tradición continental, que en un principio concibieron al stare decisis como fuente auxiliar del derecho con un carácter meramente persuasivo, actualmente se hayan inclinado por incorporar el estatus obligatorio a ciertas decisiones, confiriéndoles incluso, en algunas ocasiones un efecto erga omnes, cumpliendo por tanto, una verdadera función creadora del Derecho ${ }^{16}$.

Por ejemplo, en el sistema español, los tribunales judiciales ejercen una especie de función legislativa de carácter positivo y negativo respectivamente. Por un lado, mediante las denominadas "sentencias estimatorias de un recurso de interés de ley", es posible crear o modificar normas existentes; y por otro lado, también se reconoce esta calidad en las denominadas "sentencias estimatorias de un recurso de inconstitucionalidad" cuyo objeto es la derogación o expulsión de una norma del ordenamiento jurídico ${ }^{17}$.

Taruffo destaca por su parte, que en el derecho brasileño los tribunales judiciales con ocasión de una acción de revisión

14. J. CANo et al., "El Precedente en El Arbitraje Internacional", Revista de Derecho Universidad Nacional de Costa Rica, Vol. 4, 2019, p. 7.

15. M. Garcón. "La Racionalidad y el (auto) Precedente: Breves consideraciones sobre el fundamento y las implicaciones de la regla del auto-precedente", Revista de Pensamiento Jurídico, Madrid, 2011, p. 199.

16. V. ItURRALDE. N. 2, p. 199.

17. Ídem, p. 200. 
constitucional deciden acerca de la interpretación que deberá darse a determinada norma jurídica jerárquicamente inferior, resolución de tipo general y abstracta con fuerza vinculante ${ }^{18}$. Este jurista italiano encuentra también en su país natal una similitud importante, cuando la Corte de Casación prevé el sistema de resoluciones denominadas "máximas", que instituyen reglas jurídicas con diversas interpretaciones que dicho órgano ha conferido para una norma aplicable en determinado caso. Las máximas italianas, tienen el mismo carácter general y abstracto, similar a las decisiones judiciales vinculantes en los sistemas, español y brasileño, respectivamente ${ }^{19}$.

Lo cual parece asimilarse bastante bien al carácter vinculante del sistema de precedentes, únicamente existente en el Ecuador para la Corte Constitucional y el Tribunal Contencioso Electoral, con sus limitaciones formales y materiales respectivas. Se tratará esto con mayor profundidad más adelante.

En conclusión, dentro del Civil Law, si bien el principio stare decisis tuvo un origen tenue y desligado de su símil en el Common Law, desde el siglo XIX, ha ido adoptando semejantes características hasta volverse preponderante en los sistemas de esta tradición jurídica, donde su consolidación parece establecerse, sin embargo, para cierto tipo de resoluciones. Tal es el caso de los sistemas comparados que fueron descritos antes, y que con gran acierto la doctrina resalta. Dicho esto, corresponde ahora, analizar la naturaleza jurídica de la doctrina del stare decisis en el Ecuador, y su posible relación con su sistema arbitral.

\section{Posible Relación entre STARE DeCisis y la NATURAleza JURÍDICA DEL ARBITRAJE NACIONAL ECUATORIANO.}

\section{1 ¿Existe el stare decisis en el Ecuador? Una concepción escalonada.}

La Constitución de Montecristi reconoce a las decisiones emitidas por la Corte Constitucional, la Corte Nacional de Justicia

18. M. TARUFFo. N. 13, p. 88.

19. Ídem, p. 89. 
y el Tribunal Contencioso Electoral como fuente obligatoria y a su vez, creadora del Derecho, en las materias que por sus respectivas competencias, le corresponde a cada una. Dicho en otras palabras, el sistema constitucional ecuatoriano vigente, reconoce el carácter vinculante y obligatorio de ciertas resoluciones dentro de la justicia ordinaria, constitucional y electoral. El camino para encontrar el stare decisis en el ordenamiento jurídico ecuatoriano, lo determina efectivamente las condiciones normativas inherentes a cada una de ellas respectivamente.

Lo anterior es así, pues de conformidad con el numeral 8 del artículo $11^{20}$ de la Constitución de la República, el contenido de los derechos debe desarrollarse progresivamente a través de las normas, la jurisprudencia y las políticas públicas. Por otro lado, con base en el in fine del artículo $28^{21}$ del Código Orgánico de la Función Judicial, tanto los principios generales del Derecho, cuanto la doctrina y la jurisprudencia, servirán para interpretar y delimitar el campo de aplicación del ordenamiento legal, así como también para suplir la ausencia o insuficiencia de las disposiciones que regulan una materia, por tanto, se concede a los órganos jurisdiccionales la capacidad de interpretar y crear Derecho a través de la jurisprudencia y así, en teoría, cumplir con el mandato constitucional.

Sin embargo, en la justicia ordinaria, el papel creador del Derecho solamente es verificable cuando se dan los supuestos necesarios para lo dispuesto por el artículo $185^{22}$ de la Constitución de la República, esto es, una triple reiteración de fallos que coincidan en la misma opinión (ratio decidendi) sobre un mismo punto de Derecho, que al remitirse al Pleno de la Corte Nacional de Justicia, por medio de cuyo pronunciamiento así lo declare, o sin tal pronunciamiento haya transcurrido el plazo establecido para tal cometido, constituirá jurisprudencia obligatoria con efecto erga omnes y con vinculatoriedad horizontal y vertical. En este orden de ideas, es importante mencionar que, para la justicia ordinaria no se reconoce la presencia del stare decisis, como su esencia lo requiere, conforme lo que ha sido descrito hasta el momento.

20. Constitución de la República del Ecuador, Artículo 11 (8), RO 449, 20/10/2008.

21. Código Orgánico de la Función Judicial, Artículo 28, RO Sup. No. 544, 09/03/2009.

22. Constitución de la República del Ecuador, Artículo 185, RO 449, 20/10/2008. 
Esto representa un verdadero problema para la efectiva compatibilidad de la doctrina del stare decisis en el Ecuador. Una serie de requisitos y trabas formales lo hacen indudablemente inviable, afectando gravemente al desarrollo de la jurisprudencia y obligando en la mayoría de los casos a remontarse a decisiones y fallos de triple reiteración de hace casi ya tres décadas. Precisamente frente a este gran problema, y dado que el sistema arbitral en parte también pretende mejorarse a sí mismo a partir de las deficiencias y flaquezas del sistema ordinario de administración de justicia, la incorporación del stare decisis a dicho sistema representaría una ventaja indiscutible, no solo por la sofisticación del razonamiento jurídico expuesto en las rationes decidenci de cada laudo, sino también por la dedicación, detenimiento y especialización de los tribunales arbitrales al resolver una controversia, misma que termina con un laudo, que casi en la totalidad de ocasiones, es verdaderamente plausible y cuya materialidad y contenido no debe perderse al fin de la controversia. Dicha ventaja será tratada con mayor detenimiento más adelante.

Frente al problema con la justicia ordinaria, la presencia del stare decisis, es mayormente verificable en materia electoral y constitucional, tal vez porque se encuentran libres de la serie de las formalidades prescritas para la Corte Nacional. En el primer caso, de acuerdo con el in fine del artículo $221^{23}$ de la Constitución, se reconoce el carácter obligatorio y vinculante de las resoluciones del Tribunal Contencioso Electoral con efecto erga omnes, con la salvedad de que materialmente quedan reducidas a controversias exclusivamente en dicha materia. Para el segundo caso, el numeral 6 del artículo $436^{24}$ de la Constitución, determina que la Corte Constitucional dentro de sus atribuciones, expedirá sentencias que constituyan jurisprudencia vinculante sin otro formalismo ulterior, respecto de las acciones ordinarias y extraordinarias de protección, hábeas corpus, hábeas data, acceso a la información pública y demás procesos constitucionales para cuyo conocimiento tenga competencia. Puede decirse entonces, que la atribución conferida a este órgano, sí que constituye una aplicación verdadera del stare decisis en el Ecuador.

Basta con revisar la jurisprudencia de la Corte Constitucional, para verificar la consolidación del stare decisis, cuando dicho órgano

23. Constitución de la República del Ecuador, Artículo 221, RO 449, 20/10/2008.

24. Constitución de la República del Ecuador, Artículo 436 (6), RO 449, 20/10/2008. 
manifiesta que las diversas magistraturas deben someterse a sus decisiones, pues caso contrario se pondría en riesgo principios como la seguridad jurídica y la tutela judicial efectiva ${ }^{25}$.

En otra resolución, la Corte determinó con carácter de elemento esencial en un Estado de derechos y justicia el respeto a la regla del stare decisis, que vincula la decisión pasada a la resolución futura, con objeto de garantizar la igualdad en la aplicación del ordenamiento jurídico, la seguridad jurídica y la tutela efectiva de los derechos ${ }^{26}$. Posteriormente, este órgano a través de una resolución ulterior, continuó fortaleciendo el stare decisis en el Ecuador sobre la base de dos grandes supuestos, por un lado, a modo general, ha ratificado que constituye un deber de los operadores de justicia para adherirse a lo resuelto en el pasado y no contradecir lo decidido sin una razón debidamente fundamentada y; por otro lado, de forma concreta determina la existencia del principio stare decisis en los numerales 1 y 6 del artículo 436 de la norma normarum ecuatoriana ${ }^{27}$.

La razón jurídica detrás de lo antes descrito, viene dada efectivamente por el carácter obligatorio que tiene el stare decisis en el sistema anglosajón, incorporado al actuar de la Corte Constitucional. Esto resulta a su vez, conciliable con lo sostenido por Oyarte, quien menciona que cuando la Corte Constitucional resuelve un asunto sometido a su conocimiento, primero debe decidir qué normas y principios son aplicables a los hechos del caso, y luego debe interpretar las normas a aplicar en el caso, pero lo hace con sujeción a los cánones de interpretación constitucional. Si la más alta magistratura en materia constitucional interpreta la norma de una forma determinada, no sería admisible que otros órganos apliquen su ratio decidendi, de forma diversa ${ }^{28}$.

En tal virtud, de acuerdo con el constitucionalista ecuatoriano, estaríamos frente una situación de inseguridad jurídica si la Corte Constitucional no guarda consecuencia con sus propios fallos, pues

25. Corte Constitucional del Ecuador. Resolución No. 2, Sentencia No. 002-10-SCN-CC, RO Sup. No. $159,26 / 03 / 2010$.

26. Corte Constitucional del Ecuador. Resolución No. 40, Sentencia No. 040-14-SEP-CC, RO Sup. No. 230, 22/05/2014.

27. Corte Constitucional del Ecuador. Resolución No. 191, Sentencia No. 191-16-SEP-CC, RO Sup. No. 865, 19/10/2016.

28. R. Oyarte, Derecho Constitucional. Ed. Corporación de Estudios y Publicaciones, 2da. Ed., 2016, pp. 98-99. 
nunca se podría saber con certeza, cómo se fallarán asuntos que comparten identidad material $\mathrm{u}$ objetiva. Tal criterio también fue recogido en la sentencia No. 016-10-SEP-CC, en donde este órgano citando al tratadista Eduardo Espín, manifestó textualmente lo siguiente:

La seguridad jurídica, señala Eduardo Espín, ha de entenderse como la regularidad o conformidad a Derecho y la previsibilidad de la actuación de los poderes públicos y muy especialmente, de la interpretación y aplicación del Derecho, por parte de las Administraciones Públicas y de los jueces y tribunales. Esta previsibilidad en la actuación de autoridades, entre ellos los jueces, excluye la posibilidad de modificación arbitraria de situaciones jurídicas preexistentes (... ${ }^{29}$.

Sin perjuicio de lo anterior, Oyarte también afirma que el sometimiento a esa modalidad ecuatoriana de stare decisis no puede ser irracional. La invocación de precedentes no puede ser mecánica, pues en virtud de este principio, el tribunal debe estar de acuerdo siempre con los motivos por lo que se dictaron las sentencias anteriores, es decir su ratio decidendi, además de determinar que el caso aparentemente análogo en realidad responda a los precedentes $\mathrm{o}$, en su defecto, determinar si no han variado las circunstancias que deben motivar el fallo ${ }^{30}$. Tal afirmación ha sido señalada con gran acierto por la Corte Constitucional, cuando ha reafirmado que el stare decisis si bien guarda cierta relación con la regla del precedente vinculante en el sistema anglosajón, no son en esencia lo mismo, en virtud de que, sus formalismos por definición, resultan diferentes para la aplicación de uno u otro ${ }^{31}$.

En definitiva, en el Ecuador el stare decisis, solamente guarda cierta relación cercana a su estructura antecesora del Common Law, en las resoluciones de la Corte Constitucional y del Tribunal Contencioso Electoral, no así para la justicia ordinaria, que más bien, se ha reservado al formalismo de su estructuración, a partir de la concepción de jurisprudencia clásica al más puro estilo del

29. Corte Constitucional del Ecuador, Sentencia No. 016-10-SEP-CC, RO Sup. No. 202, 28/05/2010.

30. R. Oyarte, N. 28, p. 101.

31. Corte Constitucional del Ecuador. Sentencia No. 002-10-SCN-CC, RO Sup. No. 159, 26/03/2010. Corte Constitucional del Ecuador. Sentencia No. 028-10-SCN-CC, RO Sup. No. 319, 12/09/2010. 
Civil Law. Puede verse también que en el Ecuador la aplicación del stare decisis no implica obligatoriedad irracional, y en función del distinguishing o del overruling, no existe impedimento alguno para apartarse de una resolución anterior y favorecer a la actividad creadora del Derecho. Determinándose así la existencia del stare decisis, pero bajo una concepción verdaderamente escalonada.

\section{2 ¿Existe una relación posible y conciliable entre la naturaleza jurídica del arbitraje en el Ecuador y el stare decisis?}

La Constitución del Ecuador reconoce en su artículo 19032, al arbitraje, la mediación y otros procedimientos alternativos de solución de conflictos, determinando que sus respectivos procedimientos, se aplicarán con sujeción a la ley, en materias en las que por su naturaleza se pueda transigir.

La Ley de Arbitraje y Mediación en su artículo $1^{33}$ define al sistema arbitral como un mecanismo de solución de conflictos al cual las partes pueden someter de mutuo acuerdo, las controversias susceptibles de transacción, existentes o futuras para que sean resueltas por tribunales de arbitraje administrado o por árbitros independientes o ad-hoc.

En tal virtud, para someter una disputa a arbitraje, los artículos 5 y 6 de la referida Ley, establecen dos mecanismos. Primero, el convenio arbitral, que puede tener la modalidad de cláusula compromisoria, previa al conflicto, o de compromiso arbitral, cuando el conflicto se ha suscitado, solamente estableciendo el requisito de que conste por escrito ${ }^{34}$. Segundo, cuando se pueda abstraer o resulte del intercambio de cartas o de cualquier otro medio de comunicación que deje constancia de la voluntad de las partes de someterse a arbitraje, cuando el convenio no conste o no exista por escrito, o en su defecto, cuando presentada la demanda arbitral, por una parte, no sea objetada por la otra en su contestación ${ }^{35}$. Una vez corroborada la intención de las partes de someterse al arbitraje,

32. Constitución de la República del Ecuador, Artículo 190, RO 449, 20/10/2008.

33. Ley de Arbitraje y Mediación, Artículo 1, RO 417, 14/12/2006.

34. Ley de Arbitraje y Mediación, Artículo 5, RO 417, 14/12/2006.

35. Ley de Arbitraje y Mediación, Artículo 6, RO 417, 14/12/2006. 
se despliega la inevitabilidad del arbitraje, desencadenando así, sus efectos negativo y positivo respectivamente ${ }^{36}$.

Ahora bien, ciertamente en el Ecuador el arbitraje se fundamenta en la teoría mixta o híbrida, pues, por un lado reconoce el origen contractual y voluntario de las partes de pactar mediante un convenio -o abstraer a falta de aquel su existencia mediante cruce de comunicaciones-, someter sus disputas a dicho método de solución de controversias; y por otro, verificado lo anterior, confiere y designa al tribunal, una misión arbitral de conformidad al procedimiento elegido por las partes, o en su defecto, de conformidad al procedimiento establecido por una institución que lo administre ${ }^{37}$.

Sin embargo, contrario a la generalidad jurídica de los sistemas arbitrales, en el arbitraje ecuatoriano se destaca un elemento de particular consideración a efectos del presente trabajo. A partir de la lectura del artículo $34^{38}$ de la Ley de Arbitraje y Mediación, se desprende que la característica de confidencialidad del arbitraje en el Ecuador es facultativa y carece de obligatoriedad, lo cual se extiende también al supuesto en que las partes guarden silencio respecto a dicha característica en el convenio arbitral, o nada pueda abstraerse del intercambio de comunicaciones entre ellas. Es así llamativo que en el sistema arbitral ecuatoriano la publicidad sea la regla general y la confidencialidad su excepción.

Por lo mismo, al no exigirse legalmente que los arbitrajes en el Ecuador sean confidenciales, nada impide que tanto el procedimiento arbitral, como las resoluciones contenidas en los respectivos laudos tengan carácter público y sean, por lo tanto, accesibles a todo interesado. Entonces, de resultar posible conciliar lo sostenido por Caivano, respecto a que el arbitraje en Derecho es fundamentalmente una actividad relacionada con la interpretación y aplicación del derecho, en una concepción puramente jurisdiccional ${ }^{39}$, podría inferirse sin problema, que esta particularidad del sistema arbitral ecuatoriano permitiría dar

36. Ley de Arbitraje y Mediación, Artículo 7, RO 417, 14/12/2006.

37. F. GonzÁlez De Cossío. "Sobre la Naturaleza Jurídica del Arbitraje. Homenaje a Don Raúl Medina Mora", Revista Universidad Iberoamericana de México, p. 15. <https://bit.ly/2VBXNBP>, $(11 / 03 / 2021)$.

38. Ley de Arbitraje y Mediación, Artículo 34, RO 417, 14/12/2006.

39. R. Caivano. Arbitraje, Ed. AD-HOC, 2da. Ed., Buenos Aires, pp. 96-98. 
cabida a un ordenamiento jurisprudencial de los fallos emitidos por los tribunales arbitrales de los distintos centros de Arbitraje e incluso de aquellos ad-hoc.

Sin duda alguna, de ser así, lo anterior denotaría una posible y conciliable relación con la aplicabilidad del stare decisis en el sistema arbitral ecuatoriano. Para tal efecto, es necesario determinar las características del laudo arbitral en el sistema ecuatoriano y encontrar la posibilidad de que este guarde relación conciliable con lo sostenido hasta el momento.

\section{3 ¿El laudo arbitral en el Ecuador resulta conciliable como elemento que coadyuve a la viabilidad del stare decisis en el sistema arbitral ecuatoriano?}

La resolución de la controversia por parte de un tribunal arbitral a través del respectivo laudo, tiene relevancia vinculante exclusivamente respecto de las partes protagonistas del conflicto. Con base en la Ley de Arbitraje y Mediación, se establecen algunas características del laudo arbitral, necesarias de ser destacadas. En primer lugar, el artículo $26^{40}$ de la referida Ley, exige que el laudo -y demás decisiones del Tribunal- se expidan por mayoría de votos, y, que sean firmadas por todos los árbitros, permitiendo también la oportunidad de votos disidentes o inconformes con el de mayoría.

Segundo, el laudo arbitral es en esencia, inapelable. Contra un laudo arbitral no cabe más acciones que la acción extraordinaria de protección y; la de nulidad como efectivamente lo afirma el artículo $31^{41}$ de la referida Ley, y conforme las causales que dicha disposición establece. Finalmente, el laudo arbitral tiene el carácter de sentencia ejecutoriada, susceptible de ser ejecutado forzosamente en un procedimiento judicial ${ }^{42}$.

En virtud de lo anterior, puede verificarse que la Ley de Arbitraje y Mediación no menciona nada respecto de la aplicación del stare decisis en la resolución de controversias futuras, mucho menos respecto al desarrollo de la jurisprudencia arbitral, cuando

40. Ley de Arbitraje y Mediación, Artículo 26, RO 417, 14/12/2006.

41. Ley de Arbitraje y Mediación, Artículo 31, RO 417, 14/12/2006.

42. Código Orgánico General de Procesos, Artículo 363 (2), RO Sup. No. 506, 22/05/2015. 
claramente, al no ser obligatoria la confidencialidad, y como consecuencia de ello, el arbitraje sea generalmente de carácter público, podría bosquejarse de esta forma la base conceptual para una sistematización de recopilación de resoluciones arbitrales que contengan argumentaciones y razonamientos valiosamente especializados que podrían emanar del sistema arbitral y que difícilmente podrían encontrarse en la justicia ordinaria.

En consecuencia, si el principio de publicidad procesal, además de ser una garantía del debido proceso, constituye también la base para el nacimiento y desarrollo de la jurisprudencia de los tribunales ordinarios de administración de justicia, nada debería impedir que pueda incorporarse al arbitraje nacional la misma modalidad recopilatoria de resoluciones con miras hacia una jurisprudencia arbitral que cumpla por un lado, el desarrollo del sistema arbitral ecuatoriano en virtud del rezago producido por la propia Ley de Arbitraje y Mediación, y por otro, favorecer al estudio analítico de las argumentaciones y razonamientos jurisdiccionales, desde un aspecto académico del arbitraje, mucho más aún si dicha Ley prevé esta posibilidad al sustraer la obligatoriedad de la confidencialidad del arbitraje en el Ecuador.

Definitivamente, las características del laudo arbitral en el sistema ecuatoriano junto con el procedimiento que lleva a su dictamen efectivamente prevén un régimen conciliable con todo lo sostenido en este trabajo, de manera que, se han encontrado puntos conciliables entre la doctrina tradicional del stare decisis, con la normativa nacional ecuatoriana y más estrechamente en las secciones precedentes, con respecto a su cercanía con su sistema arbitral. Sin embargo, resulta ahora necesario expandir el presente análisis a fin de verificar más puntos conciliables en el derecho arbitral comparado.

\section{4. ¿ES VERIFICABLE LA APLICACIÓN DEL STARE DECISIS EN LA PRÁCTICA JURISPRUDENCIAL DEL ARBITRAJE INTERNACIONAL DE INVERSIONES? ¿PUNTOS CONCILIABLES CON EL SISTEMA ARBITRAL ECUATORIANO?}

Elvalor delstare decisis en el arbitrajeinternacional deinversiones ha ido in crescendo. Hoy en día, resulta verificable en virtud de 
la publicidad de los laudos emitidos en este tipo de arbitraje, ya que de la revisión de aquellos pueden evidenciarse innumerables referencias a otros laudos dictados con anterioridad, con el fin de imitarlos o apartarse de ellos, en función del distinguishing o bien, del overruling ${ }^{43}$. En cualquier caso, la fundamentación expuesta para cada caso ha sido realmente plausible.

Lo anterior ha dado cabida a una práctica bastante destacable, en donde el stare decisis permite que el precedente arbitral, sea en reiteradas ocasiones utilizado incluso por las partes para fundamentar sus pretensiones, sobre la base del razonamiento expuesto por los diversos tribunales en sus rationes decidendi, sobre determinados puntos del Derecho de inversiones, precisamente porque abordan una calidad jurídica de sofisticada estructuración ${ }^{44}$.

A diferencia del arbitraje comercial internacional, el arbitraje internacional de inversiones se caracteriza por ser una clase de jurisdicción internacional. Esto implica que, el árbitro decide en nombre de la comunidad internacional y, por tanto, el orden jurídico o lex fori del árbitro es el derecho internacional público ${ }^{45}$. La misma internacionalidad se persigue en la elección del derecho aplicable y las normas de procedimiento.

Con respecto al valor especial que representa el contenido de los laudos correspondientes a este tipo de arbitraje y la importancia del stare decisis, Douglas ha destacado esa importancia, de forma comparativa, con la actividad de la Corte Internacional de Justicia (CIJ), puesto que, un laudo o una decisión verdaderamente internacional, debe su existencia y fuerza vinculante al orden jurídico internacional y es indiferente a cualquier recurso ante un tribunal nacional y por lo mismo, solo un tribunal internacional es competente para conocer las reclamaciones relativas a la validez de un laudo arbitral verdaderamente internacional, en donde los fundamentos de dicha decisión, ciertamente no han sido corrientes

43. D. Bentolila. "Hacia una jurisprudencia arbitral en el arbitraje internacional de inversiones", Anuario Mexicano de Derecho Internacional. Instituto de Investigaciones Jurídicas Universidad Autónoma de México, Décimo Aniversario, 2012, pp. 373-420.

44. Ídem, p. 374.

45. Z. Douglas. The Hybrid Foundations of Investment Treaty Arbitration, Oxford University Press. British Yearbook of International Law, Ed. BYIL, 2003, p. 151. 
sino más bien, altamente sofisticados ${ }^{46}$. De manera que, el papel o valor de cada laudo es sumamente importante, pues en un punto conciliable, los mismos responden en último término, no solo a las partes, sino también a la creación del Derecho de inversiones de la comunidad internacional ${ }^{47}$.

Ahora bien, como menciona Gerhardt, podría discutirse la dificultad que supondría que los árbitros se sigan unos a otros en sus decisiones, debido a sus distintas nacionalidades, distintas tradiciones jurídicas o inclusive distintas profesiones, lo que no ocurriría en un tribunal permanente ${ }^{48}$. Sin embargo, conforme lo sostenido por Wälde, el arbitraje está poco determinado por las culturas específicas o tradiciones legales nacionales y las reglas del arbitraje tienden a expresar una síntesis cuyo objeto ha sido conciliar progresivamente a los sistemas Civil Law y Common Law ${ }^{49}$. Precisamente la obra de ese autor se centra en la publicidad de los laudos arbitrales en un contexto que favorezca a la construcción de una jurisprudencia arbitral en donde el stare decisis es elemento fundamental.

En el arbitraje de inversiones, los árbitros por lo general tienen acceso a las decisiones de otros tribunales ya que un gran número de laudos son públicos. Y esto ha producido un efecto bastante favorecedor tanto para este tipo de arbitraje, como para los arbitrajes comerciales internacionales, en los cuales, si bien la publicación del laudo depende del consentimiento de las partes, estas por lo general no se oponen a dicha publicidad ${ }^{50} \mathrm{y}$ permiten en consecuencia a los centros de arbitraje ${ }^{51} \mathrm{y}$ a diversas revistas

46. Z. Douglas. "The International Law of Investment Claims", Cambridge University Press, 2009, p. $101 .<$ https://bit.ly/3EdGokc>, (03/04/2021).

47. J. W. SALACUSE. "Towards a Global Treaty on Foreign Investment: The Search for a Grand Bargain". Citado en: D. Bentolila. N. 43, p. 387.

48. M. J. Gerhardt, "The limited Path Dependency of Precedent", William \& Mary Law School Publications, Faculty Publications, Williamsburg, VA, 2005, p. 903. <https://bit.ly/3A6mBRb>, $(15 / 04 / 2021)$.

49. T. WäLdE. "Condifential Awards as Precedent in Arbitration. Dynamics and Implication of Award Publication". Citado en: E. Gaillard y Y. Banifatemi. "Precedent in International Arbitration”, Ed. Juris Publishing Inc., Huntington, NY, 2007, pp. 113-135. <https://bit.ly/3C$6 \mathrm{~F} 0 \mathrm{hv}>,(21 / 04 / 2021)$.

50. Ídem, p. 123.

51. Cámara de Comercio Internacional, [CCI], "Collection of ICC Awards. Collection of Procedural Decisions in ICC Arbitration". <https://bit.ly/3nmnt0K>, (22/04/2021). Citado en: D. BENTOLILA. N. 43, p. 388. 
jurídicas especializadas que los publiquen $^{52}$ y favorezcan su desarrollo progresivo.

En tal virtud, conviene en este momento analizar la aplicación del stare decisis por parte de los tribunales de este tipo de arbitraje, pues como se mencionó al inicio de esta sección, la aplicación del stare decisis en la construcción del precedente arbitral para la fundamentación y decisión de controversias ha ido, considerablemente in crescendo. Por ejemplo, en el caso Sempra c. Argentina el tribunal arbitral que decidió la controversia, se refirió al caso Goetz, Enron y CMS, en los siguientes términos:

Este Tribunal no tiene razones para apartarse de esa conclusión, aun cuando los elementos de hecho de cada controversia puedan tener algunas diferencias. Si el propósito del Tratado y los términos de sus disposiciones tienen la amplitud con que fueron negociados y aceptados no podrían ellos, como se ha señalado, ser desconocidos por el Tribunal pues privarían al Tratado de todo efecto útil ${ }^{53}$.

Por otro lado, en el caso SGS c. Filipinas, a pesar de que el tribunal decidió adoptar una interpretación más amplia de la cláusula paraguas, se refirió también a ciertas decisiones precedentes a fin de distinguirlas con el caso en cuestión, explicando y argumentando por qué se apartaba de la resolución casi similar, emitida en el caso SGS c. Pakistán, resaltando los motivos de divergencia, analizando las razones aducidas por el tribunal en dicho caso, para dar en último término una interpretación más restrictiva al caso mencionado al inicio de este párrafo ${ }^{54}$.

Ciertamente, en el arbitraje internacional de inversiones los tribunales han tratado con distinto valor a las decisiones arbitrales precedentes. A partir de un análisis de las controversias en materia de inversiones, tanto CIADI como ad-hoc, pueden abstraerse dos

52. International Law Materials, (JDI, ICA Yearbook). "International Law Reports".

$<$ HYPERLINK "https://oxia.ouplaw.com/\%3e;" https://oxia.ouplaw.com/>; < HYPERLINK "https://www.italaw.com/" https://www.italaw.com/>, (23/04/2021).

53. Centro Internacional de Arreglo de Diferencias Relativas a Inversiones, Caso CIADI. No. ARB/02/16. Sempra Energy International c. República Argentina. Decisión sobre jurisdicción, 11/05/2005. <https://oxia.ouplaw.com/>, (25/04/2021).

54. Centro Internacional de Arreglo de Diferencias Relativas a Inversiones, Caso CIADI No. ARB/02/6. SGS. Société Générale de Surveillance S.A. c. República de Filipinas. Decisión sobre jurisdicción, 29/01/2004 (8 ICSID Rep. 518, 2005), pp. 120-124. <https://oxia.ouplaw. $\mathrm{com} />,(25 / 04 / 2021)$. 
grandes corrientes del valor del precedente arbitral resultante de la aplicación del stare decisis. En la primera corriente, el árbitro tiene la facultad de citar precedentes; para la segunda corriente, el árbitro tiene además el deber de desarrollar y respetar la jurisprudencia arbitral.

Con respecto a la primera corriente, dentro del caso AES $c$. Argentina, el tribunal declaró que la misión limitada del árbitro no le impide seguir precedentes arbitrales, pero que ello no se le impone $^{55}$. En dicho caso, Argentina opuso entre otras excepciones, que la accionista no tenía ius standi para reclamar por los daños de la sociedad en la que participa y que la diferencia no tenía relación directa con la inversión. Así, en contra de tales excepciones AES citó como parte de su argumentación jurídica los casos Azurix, CMS, LGEE, Enron y Siemens A.G. ${ }^{56}$, en los que los tribunales habían admitido las demandas presentadas por los accionistas, con ocasión de ciertas medidas dirigidas contra la sociedad local.

Contra esa argumentación, Argentina alegó que dada la naturaleza especial de cada tratado y su carácter de lex specialis, el tribunal arbitral no puede seguir precedentes arbitrales ya que ello sería contrario al principio de consentimiento en que está basado el arbitraje $^{57}$. El Tribunal indicó que, si los casos y la base jurisdiccional en estos tribunales presentan un alto nivel de similitud o, aún más, una identidad, no está esencialmente prohibido, considerar la posición expresada por estos otros tribunales.

Dada la similitud entre los casos citados, el tribunal decidió seguir los precedentes presentados por la demandante, declarando

55. Centro Internacional de Arreglo de Diferencias Relativas a Inversiones, Caso CIADI No. ARB/02/17. AES Corporation c. República Argentina. Decisión sobre jurisdicción, 26/04/2005, p. $27,<$ https://bit.ly/3ldfZdI $>,(25 / 04 / 2021)$.

56. Centro Internacional de Arreglo de Diferencias Relativas a Inversiones, Caso CIADI No. ARB/ 01/12. Azurix Corp. Argentina, Decisión sobre Jurisdicción, 8/12/2003; Centro Internacional de Arreglo de Diferencias Relativas a Inversiones, Caso CIADI No. ARB/02/1. LG\&E International Inc., c. Argentina. Decisión sobre Jurisdicción, 30/04/2004; Centro Internacional de Arreglo de Diferencias Relativas a Inversiones, Caso CIADI No. ARB/01/08. CMS c. Argentina. Decisión sobre Jurisdicción, 17/06/2003, párrafos 36-65; y Centro Internacional de Arreglo de Diferencias Relativas a Inversiones, Caso CIADI No. ARB/02/8. Siemens A.G., c. Argentina. Decisión sobre Jurisdicción, 3/08/2004. <https://bit.ly/3A2mvds> (26/04/2021). Citado también en: D. BENTOLILA. N. 43, p. 391.

57. Centro Internacional de Arreglo de Diferencias Relativas a Inversiones, Caso CIADI No. ARB/02/17. AES Corp., c. Argentina. Decisión sobre Jurisdicción, 26/04/2005. <https://bit. ly/31fIxDv>, (26/04/2021). 
sin embargo, que a pesar de que existan similitudes entre los casos, las bases de competencia y las reglas aplicables, cada tribunal sigue siendo independiente y puede emitir libremente una solución diferente para resolver el mismo problema ${ }^{58}$, para lo cual como hemos visto, recurrirá al distinguishing o al overruling.

Para la segunda corriente, en la que el árbitro tiene el deber de desarrollar y respetar la jurisprudencia arbitral, en especial las soluciones establecidas en una serie consistente y relevante de casos anteriores, tales como Austrian Airlines, Bayindir, Saipem y Burlington Resources $^{59}$. Una particularidad adicional de todos ellos, es que sus tribunales estuvieron presididos por Gabrielle Kaufmann-Kohler, por lo que contienen un párrafo similar que, luego de la sección de dichos laudos titulada como: "La relevancia de otras decisiones $\mathrm{u}$ otros laudos arbitrales", declara lo siguiente:

El tribunal considera que las decisiones de otros tribunales no son vinculantes. Al mismo tiempo, es de la opinión que debe considerar decisiones previas. El tribunal considera que, salvo motivos apremiantes en contrario, tiene el deber de adoptar las soluciones establecidas en una serie de casos consistentes. Asimismo, considera que, sujeto a las especificidades del tratado específico y de las circunstancias del caso concreto, tiene el deber de contribuir al desarrollo armonioso del derecho de las inversiones y, por tanto, de satisfacer las expectativas legítimas de la comunidad de estados y de inversores, en pos de la previsibilidad del estado de derecho ${ }^{60}$.

Dicha posición ha sido compartida por otros tribunales y comités de anulación del CIADI. Por ejemplo, en la anulación del caso $M C I$-que fue repetido también por el comité de anulación en el caso Enron-, el tribunal arbitral, luego de mencionar el papel limitado de los comités ad-hoc, declaró que "la responsabilidad de asegurar consistencia en la jurisprudencia y de crear un cuerpo coherente de reglas reside principalmente en los tribunales de

58. Ídem, p. 30.

59. Centro Internacional de Arreglo de Diferencias Relativas a Inversiones, Caso CIADI No. ARB/08/5. Burlington Resources c. Ecuador. Decisión sobre Jurisdicción, 2/06/2012, (cita casos Centro Internacional de Arreglo de Diferencias Relativas a Inversiones, CIADI Austrian Airlines c. Eslovaquia; Bayindir c. Pakistán). $<\mathrm{https} / / / \mathrm{bit} .1 \mathrm{l} / 3 \mathrm{k} 54 \mathrm{u} 8 \mathrm{~V}>,(27 / 04 / 2021)$.

60. Ídem. 
inversiones y no en los comités de anulación" ${ }^{\prime 1}$. De manera que, desde el punto de vista de los objetivos y fines del stare decisis, de conformidad con su aplicación en este tipo de arbitraje, se cumple tanto con la previsibilidad, cuanto con la seguridad jurídica.

Como sostiene Popelier, las expectativas legítimas de las partes respecto al resultado, así como la publicidad y claridad de sus decisiones, favorecen a que el recurso al precedente sea una facultad del tribunal arbitral con miras a la construcción de una jurisprudencia arbitral que caracterice al arbitraje de este tipo. Tal es así, que incluso las partes han sustentado sus argumentos en decisiones anteriores, exigiendo y demostrando en cambio, la presencia de cierta previsibilidad y una suerte de status quo, que recogen las mejores y más brillantes interpretaciones de Derecho, desde un contexto mayormente especializado, frente a posibles concepciones anacrónicas de la justicia ordinaria.

Finalmente, respecto a este tipo de arbitraje y también aplicado a la generalidad de los diversos procedimientos arbitrales, sean nacionales e internacionales, Bentolila ${ }^{62}$ precisa cuatro razones por las cuales los tribunales se citan o deberían citarse entre sí, basándose en la actividad reiterada de aquellos al incorporar el stare decisis. La primera razón consiste en su utilidad, pues los tribunales se refieren a su valor ilustrativo, instructivo ${ }^{63}$, útil ${ }^{64}$, o en general como fuente de inspiración para casos futuros ${ }^{65}$.

La segunda razón tiene relación con la coherencia al momento de seguir lo establecido en una línea de casos a fin de velar por el desarrollo de las inversiones y su previsibilidad conflictual, sobre la

61. Centro Internacional de Arreglo de Diferencias Relativas a Inversiones, Caso CIADI No. $\mathrm{ARB} / 03 / 16$. ADC Affiliate Ltd y ADC \& ADMC Management Ltd c. Hungría, Laudo, 27/09/2006, p. 293. <https://oxia.ouplaw.com/>, (26/04/2021).

62. D. Bentolila. N. 43.

63. K. Kohler. Arbitral Precedent, Ed, International Economic Law: The State and Future of the Discipline, Picker, 2008, p. 270. Citado en: D. Bentolila. N. 43.

64. Centro Internacional de Arreglo de Diferencias Relativas a Inversiones, Caso CIADI No. ARB/ 01/12. Azurix Corp. Argentina, Decisión sobre Jurisdicción, 8/12/2003 <https://oxia.ouplaw. $\mathrm{com} />,(27 / 04 / 2021)$.

65. Comisión de las Naciones Unidas para el Desarrollo del Derecho Mercantil Internacional, Caso CNUDMI/UNCITRAL, Gradn River Enterprises Six Nations Ltd., c. Estados Unidos de América. Decisión sobre jurisdicción, 20/07/2006; Centro Internacional de Arreglo de Diferencias Relativas a Inversiones, Caso CIADI No. ARB (AF)/99/1. Marvin Roy Feldman Krapa c. Estados Unidos Mexicanos. Laudo, 16/12/2002, P. 107. <https://oxia.ouplaw.com/> (28/04/2021). Citado en: D. BENTOLILA. N. 43, p. 392. 
teoría económica de la "elección racional" ${ }^{66}$ aplicada al derecho, a fin de analizar el comportamiento de los jueces y el impacto que el precedente tiene a la hora de decidir, tanto en este tipo de arbitrajes, cuanto en la generalidad de los mismos.

Las siguientes razones expuestas por Bentolila, se relacionan con sus efectos estratégicos y pragmáticos. Así, la tercera razón consiste en la incorporación de precedentes arbitrales en el sustento de las pretensiones de las partes, convirtiéndolo además en el lenguaje del proceso que legitima su referencia por el tribunal ${ }^{67}$. Finalmente, la cuarta razón supone que el modo de decidir represente un consenso, en la medida de que los árbitros son libres de seguir precedentes o no, siendo la referencia o recurso a un precedente, una aceptación del criterio decisorio, un visto bueno sobre determinada ratio decidendi ${ }^{68}$, previo a su incorporación en el caso concreto.

En conclusión, pueden observarse nuevamente puntos conciliables entre este tipo de arbitraje y el sistema arbitral ecuatoriano, principalmente guiados por la característica de publicidad de sus laudos y procedimientos, de manera que, marcan el punto de partida también para el conocimiento y estudio académico del arbitraje en general.

Por otro lado, marca también un factor determinante en la construcción de una jurisprudencia arbitral, elemento de necesaria consideración para el sistema arbitral ecuatoriano. Ahora es necesario observar la práctica verificable en el arbitraje comercial internacional y de ser posible, encontrar nuevos puntos conciliables a efectos del presente trabajo.

\section{1 ¿Es asimismo verificable el stare decisis en el arbitraje comercial internacional? ¿Existen puntos conciliables con el sistema arbitral ecuatoriano?}

En el orden de ideas expuesto, conviene ahora analizar si los tribunales arbitrales internacionales han optado, al momento de

66. R. Posner. "Past- Dependency, Pragmatism, and Critique of History in Adjudication and Legal Scholarship", Chicago University Law Review, 2000, p. 573.

67. D. Bentolila. N. 43, p. 400.

68. Ídem, p. 401. 
decidir una controversia comercial, por fundamentar y sustentar sus decisiones observando resoluciones anteriores y análogas proferidas por otros tribunales, en el contexto materia del presente artículo respecto del stare decisis. El reconocido árbitro internacional Carlos Guaia, citando a Gary Born ${ }^{69}$ señala lo siguiente:

(...) el arbitraje de derecho-cuando se trata de la referencia a un sistema jurídico determinado- en su más exacta concepción, sólo admite los límites que las partes puedan haber acordado en su convención arbitral cuando la solución del caso, con esas restricciones, sea compatible con la ley aplicable ${ }^{70}$.

Fernández, por su parte señala la frecuencia creciente de los tribunales arbitrales al momento de recurrir a las resoluciones anteriores para fundamentar una decisión actual, apuntando a la construcción intencional o no de una jurisprudencia arbitral ${ }^{71}$. En este sentido, Merino y Chillón, indican que “(...) cada vez toma mayor cuerpo como fuente del arbitraje, especialmente en el de carácter internacional, la jurisprudencia elaborada por las cortes de arbitraje"72.

Sin embargo, frente a esa creciente tendencia a otorgarle un valor fundamental al stare decisis en el arbitraje comercial internacional Opertti ha expresado, en contrario, lo siguiente:

La ausencia de un principio de jerarquía, juega en contra de una verdadera jurisprudencia arbitral, aun cuando cabe reconocer que dificultades parecidas -aunque distintas- se dan en la jurisprudencia judicial, en especial cuando en ausencia de jueces internacionales son los de cada Estado los encargados de interpretar y aplicar los instrumentos internacionales ${ }^{73}$.

En contraste con lo referido por este autor, llama especial atención una sentencia emitida por el Consejo de Estado de Colombia en 2017, sobre la anulación de un laudo, emitido en esta clase de

69. G. Born. "International Arbitration: Law and Practice", Kluwer Law International, 2014.

70. C. Guaia. "Notas sobre arbitraje y jurisprudencia", Revista de Arbitraje de la Pontificia Universidad Católica del Perú, Lima, 2014, pp. 139-145.

71. D. Fernández Arroyo. "El auge del Arbitraje frente al debate sobre su legitimidad", Publicaciones Organización de Estados Americanos, 2013, p. 271. <https://bit.ly/3k5x4qP>, (28/04/2021).

72. J. M. Merchán y J. C. Medina. Tratado de Derecho Arbitral, Ed. Civitas, 3ra Ed., Madrid, 2006, p. 1118.

73. D. OpertTI. "El Arbitraje Comercial Internacional en el Sistema Interamericano", Departamento Asuntos Jurídicos Organización de Estados Americanos, Arbitraje Comercial Internacional, 2006, p. 21. <https://bit.ly/3k82WLr>, (29/04/2021). 
arbitraje internacional, en el que se utilizó como fundamento la teoría del stare decisis, señalando en lo pertinente lo que sigue:

(...) en criterio de la Sala los laudos arbitrales son decisiones de las cuales se deriva la existencia de precedentes judiciales habida consideración (i) de la asimilación que desde el punto de vista jurídico cabe realizar entre la sentencia judicial y el laudo arbitral, circunstancia determinante de que (ii) a los tribunales de arbitramento resulte exigible la observancia de idénticos principios constitucionales y derechos fundamentales que justifican, para los jueces, el deber de respetar sus propios precedentes, de suerte que los tribunales arbitrales se hallan en la obligación de tener en cuenta los precedentes derivados de las decisiones proferidas por otro(s) tribunal(es) de arbitramento ${ }^{74}$.

Se recurre a este fallo, por un criterio de proximidad geográfica y porque resalta, a efectos del presente trabajo, que el deber de observancia del precedente por parte de los tribunales arbitrales justifica y garantiza el cumplimiento del principio de igualdad, seguridad jurídica, buena fe, tutela efectiva y publicidad, dejando claro que para acudir a la aplicación de una decisión anterior, el tribunal arbitral debe verificar primero el cumplimiento de los parámetros análogos para identificar los precedentes contenidos en laudos arbitrales anteriores, al respecto el mismo órgano colombiano de administración de justicia, determinó lo siguiente:

(...) el precedente judicial o arbitral, en tanto que elemento jurídico que ejerce una fuerza gravitacional que atrae hacia su contenido los casos concretos que deban ser resueltos en el futuro por el mismo juez, por sus subordinados funcionales según que se trate de precedente horizontal o de precedente vertical, respectivamente- o por otro tribunal de arbitramento, solo puede estructurarse correctamente a partir de la inescindible conjunción entre (i) los hechos relevantes del caso a decidir, (ii) la subregla o criterio jurisprudencial en el cual se soporta la decisión adoptada por el juez o tribunal arbitral -la ya comúnmente llamada ratio decidendi- y (iii) la parte resolutiva del correspondiente fallo o laudo-decisum ${ }^{75}$.

74. Consejo de Estado de Colombia. Decisión sobre Anulación de Laudo Arbitral, causa No. 201600138, 8/02/2017. Citado en: J. CANO et al., N. 14.

75. Ídem. 
Lo anterior resulta relevante, pues refleja la tendencia que en algunos países, inclusive de tradición Civil Law, hacia la aceptación de la doctrina del precedente arbitral y en tanto, del stare decisis, en el arbitraje comercial internacional, a pesar de las barreras técnicas y jurídicas que han existido y que, anteriormente fueron irreconciliables. Como se manifestó en la sección anterior, la voluntad de las partes, de conferirle publicidad a sus procesos arbitrales, determina un carácter fundamental en la construcción de una jurisprudencia arbitral.

Al igual que en el caso del arbitraje internacional de inversiones, la publicidad delas resoluciones en arbitrajes comercialesinternacionales, favorecen también a la construcción dogmática y pragmática del arbitraje en general, a la par que permite a sus protagonistas recurrir al stare decisis de su práctica jurisprudencial para sustentar de mejor forma, sus pretensiones y defensas en diversos casos.

A manera de conclusión, se puede afirmar que existe un gran debate entre la mayoría de los tribunales de arbitraje comercial internacional con respecto a aceptar la doctrina del precedente como fuente creadora del derecho, en función de la aplicación del stare decisis. Sin embargo, resulta evidente que cada vez se presenta con más fuerza la inclinación de los tribunales de arbitraje de fundamentar sus decisiones en laudos anteriores con un criterio que va más allá de la complementariedad y persuasión en los argumentos del laudo, al mismo tiempo que han demostrado una dificultad cada vez mayor a apartarse de decisiones anteriores predominantes sobre casos análogos. Huelga decir que, esta tendencia aún por materializarse se funda en el principio de publicidad procesal, principio igualmente incorporado a la legislación arbitral ecuatoriana.

\section{5. ¿LA PRÁCTICA DE LA CORTE INTERNACIONAL DE JUSTICIA VERIFICA LA APLICACIÓN DEL STARE DECISIS? ¿QUÉ PUNTOS CONCILIABLES EXISTEN CON EL SISTEMA ARBITRAL ECUATORIANO?}

De conformidad con el literal d) del artículo $38^{76}$ del Estatuto de la Corte Internacional de Justicia, las decisiones judiciales constituyen un medio auxiliar para la determinación de las reglas de

76. Estatuto de la Corte Internacional de Justicia, Artículo 38 (d), 01/07/1987. 
derecho aplicables a un caso, sin perjuicio de que dichas decisiones solo sean obligatorias inter partes conforme el artículo $59^{77}$ de dicho Estatuto.

Frente a una eventual duda respecto a qué tipo de decisiones se refiere el Estatuto, doctrinariamente es pacífico que, los precedentes a tomar en cuenta por parte de la Corte Internacional de Justicia son solamente los fallos internacionales y que las decisiones de los tribunales internos entrarían en la órbita del antes mencionado artículo, con la posibilidad de contribuir solo en la creación de una norma consuetudinaria ${ }^{78}$.

De la lectura de dicho artículo, parecería que el término "decisiones judiciales" excluiría de su órbita las decisiones de los tribunales arbitrales. Sin embargo, la práctica de la Corte Internacional de Justicia demuestra efectivamente lo contrario, pues el precedente emitido a partir del caso Alabama se cita posteriormente en la sentencia sobre el caso Nottebohm (Liechtenstein c. Guatemala $)^{79}$. Demostrándose así, un punto relevantemente conciliable que además verifica una coexistencia entre sistemas de solución de controversias, que emanan de la voluntad de las partes.

Con el nacimiento de distintas jurisdicciones internacionales, puede decirse que la jurisprudencia ha alcanzado un notable valor, según Sereni, esto ha contribuido a la formación de una jurisprudencia internacional basada en el principio rerurm perpetuo similiter iudicatorum auctoritas, es decir, la autoridad de las cosas juzgadas siempre del mismo modo ${ }^{80}$. Según Lauterpacht, la práctica de la CIJ, confirma dicho principio, pues continuamente recurre a decisiones anteriores, tanto para recogerlas e interpretarlas previo a su incorporación a un caso concreto, cuanto para explicar la falta de similitud con el precedente para apartarse de él ${ }^{81}$.

77. Estatuto de la Corte Internacional de Justicia, Artículo 59, 01/07/1987.

78. H. LaUterpatch. "The Development of International Law by the International Court", Stevens and Son, Londres, 1958. Citado en: F. RAIMONDO. "Corte Internacional de Justicia, Derecho Internacional Humanitario y Crimen Internacional de Genocidio. El valor de la jurisprudencia de la Corte Internacional de Justicia como verificadora del Derecho Internacional Humanitario y el Crimen Internacional de Genocidio", Instituto de Relaciones Internacionales Universidad de La Plata, 2002. <https://bit.ly/3hrKAD7>, (29/04/2021).

79. Corte Internacional de Justicia. Caso Nottebohm. Sentencia, 18/11/1953, Recueil 1953, p. 119. $<$ https://bit.ly/3nr3Vbn>, (29/04/2021).

80. A. P. Sereni. Diritto Internazionale, Ed. Dott. A. Giuffré, Milán, 1956, p. 163.

81. H. Lauterpatch. N. 78. 
Así, en la sentencia del caso Nottebohm, resulta importante resaltar la opinión disidente del Juez Read en un segundo dictamen de 1995, pues afirma la necesidad de apreciar que la práctica del precedente para tribunales arbitrales y judiciales, en función de la teoría del stare decisis, está tan generalizada que ha llevado a los jueces a pensar continuamente que, si en un determinado caso no se han invocado precedentes es porque ellos no existen ${ }^{82}$ y conviene crearlos.

Ahora bien, de acuerdo con lo sostenido por Shahabuddeen, existe consenso en la doctrina para reconocer a la CIJ el poder y la responsabilidad de desarrollar el derecho internacional y agrega que sería muy difícil visualizar un proceso de desarrollo del derecho internacional que en algún punto no culmine en creación y que este punto se encuentra precisamente en el proceso judicial mismo, representado justamente por las decisiones de la CIJ ${ }^{83}$.

Por su parte, Manuel Díez de Velasco, determina que la función del precedente reviste un doble aspecto. Primero, como elemento de interpretación y medio de prueba, es decir, como verificador del Derecho, tal cual la forma que adopta el literal d) del artículo 38 del Estatuto de la CIJ. Segundo, tales decisiones constituyen el mejor medio para determinar qué es el Derecho, desde y para una esfera académica netamente ${ }^{84}$.

Siguiendo esta línea, de acuerdo con Miaja, las decisiones de los tribunales internacionales constituyen un medio auxiliar de las fuentes del Derecho internacional que sirve a los fines de proclamar principios fundamentales del orden jurídico internacional, así como también para aplicar a otros supuestos las soluciones previamente ofrecidas por normas convencionales o consuetudinarias ${ }^{85}$.

82. Corte Internacional de Justicia. Opinión Disidente Juez Read. Caso Nottebohm. p. 43. <https:// bit.ly/3nr3Vbn>, (29/04/2021).

83. M. Shahabuddeen. "Precedent in the World Court", Cambridge University Press, Grotius Publications, 1996, p. 91.

84. M. D. De Velasco, Instituciones de Derecho Internacional Público, Ed. Tecnos, 10ma Ed., Madrid, 137.

85. A. MiaJA. El principio de efectividad en Derecho Internacional, Valladolid, 1958, p. 95. Citado en: F. RAIMONDO. "Corte Internacional de Justicia, Derecho Internacional Humanitario y Crimen Internacional de Genocidio. El valor de la jurisprudencia de la Corte Internacional de Justicia como verificadora del Derecho Internacional Humanitario y el Crimen Internacional de Genocidio", Instituto de Relaciones Internacionales Universidad de La Plata, 2002. <https://bit. ly/3tAJolO>, (29/04/2021). 
En consecuencia, tanto en la doctrina como en la jurisprudencia internacional, el examen de la práctica de la CIJ corrobora en un modo convincente la importancia del precedente a través del stare decisis, como fuente auxiliar del derecho internacional. Si bien, la invocación de un precedente se presenta generalmente como un argumento entre otros adicionales, no parecen existir dudas de que las decisiones anteriores de los tribunales internacionales, y sobre todo de la CIJ en esta sección, producen una influencia notoria sobre el tribunal que conoce y resuelve determinado asunto.

La CIJ ha sido consecuente con sus decisiones anteriores e incluso cuando pretende no estarlo, se ha cerciorado de argumentar y explicar también, la necesidad de apartarse y emitir una nueva decisión, a partir de la diferencia existente entre precedentes vigentes frente a un nuevo caso concreto.

Ejemplo de lo antes referido, son las decisiones judiciales de la CIJ sobre las excepciones preliminares, en los casos del Templo de Préah Vihéar ${ }^{86}$ y Barcelona Traction, Light and Power Company Limited ${ }^{87}$, donde la CIJ precisó de manera muy acertada, las diferencias con el precedente existente, relativo al asunto sobre el Incidente Aéreo Búlgaro-Israel ${ }^{88}$, en relación con la declaración de aceptación de la jurisdicción obligatoria de su predecesora, la Corte Permanente Internacional de Justicia (CPIJ).

En este contexto, pueden apreciarse ciertos puntos conciliables adicionales verificables de la práctica de la CIJ con el arbitraje internacional de inversiones y tenuemente, pero con gran proyección en el arbitraje internacional comercial, con respecto al recurso a los precedentes sobre la base del stare decisis, como fundamento o medio auxiliar para encontrar la regla de derecho aplicable al caso concreto, o en su defecto, como explicación de las justificaciones (distinguishing $\mathbf{u}$ overruling), que motivarían alejarse de aquellos.

86. Corte Internacional de Justicia. Caso Temple of Préah Vihéar. Sentencia, 26/05/196, Recueil. 1961, p. 25. <https://bit.ly/38ZyWuz>, (30/04/2021).

87. Corte Internacional de Justicia. Caso Barcelona Traction, Light and Power Company, Limited (Bélgica c. España). Nueva Aplicación: 1962. Sentencia, 24/07/1964), p. 27. <https://bit.ly/3Ec1Ypm>, (30/04/2021).

88. Corte Internacional de Justicia. Caso Incidente Aéreo Búlgaro-Israelí (Israel c. Bulgaria). Sentencia, 26/05/1959), pp. 21-23. <https://bit.ly/3k5uocH>, (30/04/2021). 
En ambos casos, se cumple una labor creadora del Derecho, que puede atribuirse entre otros factores, a que en el caso de la CIJ, los procesos no se caracterizan por ser confidenciales al ser aquellos de interés comunitario internacional, tal cual ocurre en el caso del arbitraje internacional de inversiones y comercial, en donde las partes al no pactar confidencialidad, coadyuvan a la publicidad de dichos procesos y de sus decisiones, razón por la cual, amerita su incorporación en casos futuros y en consecuencia, la concreción de argumentaciones, razonamientos y criterios que al irse unificando cumplen la antes dicha labor creadora sobre un contexto sofisticado y desarrollado de las instituciones jurídicas que resultan de cada relación entre partes. Similitud compartida, y que también se plasma entre estos sistemas debido a la obligatoriedad relativa del fallo, así como en su carácter definitivo e inapelable ${ }^{89}$. Puntos definitivamente conciliables con el sistema arbitral ecuatoriano.

\section{6. ¿ES VIABLE INCORPORAR EL STARE DECISIS EN EL ARBITRAJE NACIONAL ECUATORIANO A PARTIR DE LOS PUNTOS CONCILIABLES ANALIZADOS? PROPUESTA DE REFORMA DE LA LAM PARA EL ARBITRAJE EN DERECHO.}

La ausencia de obligatoriedad legal, conforme el artículo $34^{90}$ de la Ley de Arbitraje y Mediación ecuatoriana, respecto de la confidencialidad del proceso arbitral permite que el procedimiento arbitral sea esencialmente público, adaptando, por un lado, la característica constitucional de publicidad inherente a cualquier proceso judicial ${ }^{91}$ y por otro, una concreción más sólida de aquello, sustentada por el carácter supletorio de las normas procesales vigentes $^{92}$, específicamente para el arbitraje en Derecho. En tal sentido, de conformidad al artículo $3^{93}$ de la Ley referida, cuando el arbitraje sea en Derecho y no se pacte confidencialidad, además de que los árbitros decidan sobre principios y normas jurídicas en determinado caso, al ser este y su consecuente laudo de carácter público, puede incorporarse el stare decisis, sobre la base de dos formas concretas.

89. Estatuto de la Corte Internacional de Justicia, Artículo 60, 01/07/1987.

90. Ley de Arbitraje y Mediación, Artículo 35, RO 417, 14/12/2006.

91. Constitución de la República del Ecuador, Artículo 168 (5), RO 449, 20/10/2008.

92. Ley de Arbitraje y Mediación, Artículo 37, RO 417, 14/12/2006.

93. Ley de Arbitraje y Mediación, Artículo 3, RO 417, 14/12/2006. 
En primer lugar, tal cual la práctica de la CIJ y de los tribunales arbitrales internacionales de inversiones, y la tendencia potencial de los tribunales de arbitraje comercial internacional, puede considerarse que, al no existir confidencialidad, las partes libremente pueden designar que el laudo emitido con ocasión de su controversia sea posteriormente incorporado a un compendio físico o digital a cargo de un instituto especializado en el arbitraje, su estudio y desarrollo, a fin de que cumpla una finalidad dual: por un lado, facilitar el acceso público de los interesados a las decisiones de un proceso arbitral; y por otro, la sistematización de dichas decisiones, con miras al desarrollo de una jurisprudencia arbitral, que permita, como en efecto ocurre por ejemplo con el papel de los "Yearbooks" de la Cámara de Comercio Internacional para los sistemas antes analizados, en la recopilación de las rationes decidendi de dichos fallos, para desarrollo, estudio y debate, desde el ámbito académico, así como su consideración e incorporación en casos futuros similares, ya en la esfera arbitral de las controversias.

El ideal de stare decisis que necesita el sistema arbitral ecuatoriano no sería esencialmente vinculante sin posibilidad de crear un criterio distinto, pues por medio del distinguishing o del overruling favorecerá también a esta finalidad, al argumentarse y justificarse las razones que motivarían alejarse de aquel y dictar otra decisión en su lugar. Ambos aspectos, constituyen por igual, el cumplimiento de una labor creadora del Derecho arbitral ecuatoriano.

Ahora bien, cabe preguntarse, ¿qué ocurre cuando las partes efectivamente han convenido la confidencialidad de su proceso arbitral? Previo a obtener una respuesta, conviene recalcar nuevamente que la confidencialidad si bien es inherente al arbitraje en general, en el sistema ecuatoriano aquello es una excepción particular, de manera que, en este caso igualmente podrían configurarse una vía concreta que de cabida al stare decisis, de una forma efectiva en el arbitraje nacional.

Una posible modalidad efectiva para este posible problema, podría representarse a la luz del siguiente ejemplo: un laudo que no se ha cumplido por la parte vencida y que ha sido objeto de un proceso judicial de ejecución forzosa ${ }^{94}$, en el cual, adicionalmente,

94. Código Orgánico General de Procesos, Artículo 363 (3), RO Sup. No. 506, 22/05/2015. 
no se haya discutido sobre su nulidad. En este caso, desde el momento en que la eventual demanda de ejecución de un laudo originariamente confidencial es calificada y admitida a trámite, se reviste automáticamente del principio de publicidad establecido en la Constitución ${ }^{95}$ por haberse judicializado, y que lamentablemente al no ser un proceso de conocimiento, se encuentra privado del eventual desarrollo jurisprudencial que pudiese tener en casación.

De manera que, resultaría óptimo que, cuando aquello suceda, el centro de arbitraje que administró el procedimiento, o en su defecto, el tribunal arbitral ad-hoc y sus colaboradores, si existiesen, tengan a bien adicionar este laudo al referido compendio sistematizado por parte de un Instituto Especializado de Arbitraje, que lo adicione junto a otros precedentes para su posterior recurso, con base en el stare decisis, incorporando su ratio decidenci en casos sucesivos o en su defecto, argumentando los motivos que justifican alejarse de ellos, y por tanto continuar la labor creadora del Derecho arbitral ecuatoriano.

En el caso del ejemplo anterior, conviene también preguntarse ¿qué ocurre en cambio, si el laudo arbitral es declarado nulo? Sin intención de caer en un pleonasmo jurídico, vale resaltar que, en caso de declararse nulo un laudo arbitral, este no tendrá que ser considerado en una estructura sistemática de compendio de precedentes arbitrales, pues simplemente la nulidad de aquel se traduce en ineficacia de lo resuelto en su parte fundamental o ratio decidendi, por tanto, irreconciliable con su consideración en casos futuros.

En consecuencia, la inclusión del stare decisis en la conformación de la cultura del precedente en el ámbito creador del Derecho arbitral ecuatoriano, no encuentra su fundamento en el paradigma absolutamente obligatorio del Common Law, sino más bien como referencia e inspiración para la decisión de un caso concreto, incluso para encontrar determinada norma de derecho en determinada resolución precedente.

Lo anterior entonces, no solo que es necesario, para el desarrollo de precedentes arbitrales estructurados con base en los criterios

95. Constitución de la República del Ecuador, Artículo 168 (5), RO 449, 20/10/2008. 
anteriores, sino que además es posible y puede introducirse en el sistema arbitral nacional a través de una reforma a la LAM, que podría añadirse como inciso a los artículos 5 y 34, que cuya estructuración respectiva a cada uno de ellos, a manera de propuesta, podría ser de la siguiente forma:

\section{Definición del convenio arbitral}

Art. 5. $-(\ldots)$

Inciso que podría incluirse después del segundo:

En el convenio arbitral, podrá constar también la manifestación inequívoca de las partes, que exprese su voluntad relativa a la incorporación del laudo que llegare a resolver su controversia, al sistema de precedentes arbitrales para el desarrollo de su jurisprudencia, en aplicación del principio stare decisis.

\section{Confidencialidad del proceso arbitral y stare decisis.}

Art. 34. - (...) inciso que podría añadirse a continuación de la disposición vigente:

En caso de no haberse convenido la confidencialidad del procedimiento arbitral, las partes pueden acordar libremente la inclusión del laudo que llegare a emitirse con ocasión de su controversia, al compendio de resoluciones existentes y desarrollados por la Institución Especializada de Arbitraje, que podrán ser aplicables, considerados e incorporados en casos futuros. La misma modalidad operará en el caso en que las partes no se hubieren pronunciado respecto de la confidencialidad en su convenio arbitral y en los casos de laudos que hayan sido judicializados con ocasión de una acción de ejecución.

Evidentemente, un laudo que ha sido objeto de una acción de nulidad o extraordinaria de protección no entrará en esta modalidad, hasta que la decisión sobre dichas acciones sea emitida. Finalmente, a fin de completar el presente trabajo, conviene ensayar un formato de cláusula arbitral que sería pertinente a efectos de ratificar el stare decisis, en función de la reforma propuesta anteriormente para la referida Ley, cuya estructuración sería de la siguiente manera: 
En caso de suscitarse conflicto o disputa entre las partes, estas expresamente renuncian a la jurisdicción ordinaria, fuero y domicilio y acuerdan someter dicha controversia o controversias, al conocimiento y resolución de un Tribunal de Arbitraje de (centro de arbitraje escogido por las partes / $o$ ad-hoc), que se sujetará a lo dispuesto en la Ley de Arbitraje y Mediación; el Reglamento (fijado por las partes si es ad-hoc o el del centro de arbitraje escogido por ellas, si es administrado) y las siguientes normas: a) Los árbitros serán seleccionados conforme lo establecido en la Ley de Arbitraje y Mediación (o de acuerdo a lo determinado por las partes si es ad hoc); b) Las partes renuncian a la jurisdicción ordinaria, se obligan a acatar el laudo en derecho que expida el Tribunal Arbitral y se comprometen a no interponer ningún tipo de recurso en contra del laudo arbitral, salvo las acciones que por Ley sean pertinentes; c) Para la ejecución de medidas cautelares el Tribunal Arbitral estará facultado para solicitar a los funcionarios públicos, judiciales, policiales y administrativos su cumplimiento sin que sea necesario recurrir a juez ordinario alguno; d) El Tribunal Arbitral será integrado por (número de árbitros) quien/quienes decidirán en Derecho; e) Dado que el procedimiento será (o no será) confidencial, las partes acuerdan que el laudo dictado en virtud de su controversia, sea público y forme parte de la estructura sistematizada de precedentes arbitrales, en virtud del principio stare decisis, a cargo del Instituto Especializado de Arbitraje para el desarrollo de la jurisprudencia arbitral, una vez que se encuentre ejecutoriado y ha sido cumplido voluntariamente, o se encuentre en trámite de ejecución forzosa (cursivas corresponden a la sección que podría incluirse en la cláusula arbitral); f) El lugar del arbitraje será en las instalaciones de (el centro de arbitraje administrado escogido por las partes; o el lugar del arbitraje ad-hoc).

\section{Conclusiones}

El stare decisis, ha abandonadola concepción primigenia que tuvo en el Common Law, como elemento de rigurosidad y obligatoriedad sucesiva en casos futuros, a tal punto que, actualmente constituye un principio que no necesita de la complejidad estructurada y formalista del papel de la jurisprudencia en los sistemas Civil Law y que, sin tener necesariamente el carácter de precedente o 
jurisprudencia obligatoria, cumple un papel fundamental en la argumentación jurídica y en la labor creadora del Derecho.

En el caso del Derecho arbitral internacional, sea de inversiones o comercial, se demuestra una aplicabilidad y tendencia, respectivamente a recurrir a resoluciones anteriores para fundamentar casos presentes o futuros, tal cual la práctica de la Corte Internacional de Justicia, y es precisamente el carácter voluntario para someter sus controversias a estos sistemas de resolución de conflictos, así como la ausencia del elemento de confidencialidad, puntos conciliables y semejantes entre dichos sistemas, que igualmente son semejantes con el modelo mixto guía el sistema arbitral ecuatoriano. Como se ha visto, no solo es necesaria su inclusión en el sistema arbitral ecuatoriano con miras a una jurisprudencia arbitral, sino que también es llamativamente posible. La propuesta de reforma a la Ley de Arbitraje y Mediación, así como el formato de cláusula arbitral, expuestos con ocasión del presente trabajo, así lo permitirían.

Finalmente y de forma precisa, se concluye que, la voluntad de las partes y la ausencia de obligatoriedad del carácter confidencial del arbitraje, permite la inclusión del stare decisis en el sistema arbitral ecuatoriano, y hace posible a su vez, el desarrollo de sus precedentes sobre todo porque la ratio decidendi que puede encontrarse en aquellos, deónticamente estaría provista de argumentos, razonamientos e interpretaciones normativas para el arbitraje en Derecho, que por la característica de especialidad que debería revestir a los árbitros respecto de determinadas materias, hacen necesario que sean plasmadas en resoluciones que al propio sistema arbitral no le conviene que permanezcan en forma privada y reservada, sino más bien, que a través de su publicidad, sea posible su recurso tanto para la argumentación y fundamentación de casos futuros semejantes, como también para justificar alejarse de ellos y así crear nuevas resoluciones.

En otra esfera de argumentación, podría concluirse a fortiori que si bien, la jurisdicción arbitral nace de la voluntad de las partes para someter sus controversias a arbitraje, nada impediría que sea la misma voluntad de las partes, la que también designar que los laudos emitidos en sus controversias den cabida a una necesaria jurisprudencia arbitral. En uno u otro caso, la función creadora del 
Derecho arbitral, sobre la base de la teoría del stare decisis, en función de lo expuesto en el presente artículo, es sumamente beneficiosa, como efectivamente lo han verificado los tribunales internacionales. Si gracias a ellos, se tiene en gran medida el conocimiento académico y profesional sobre temas de arbitraje cabe preguntarse ¿qué le impide entonces al Ecuador tomar esa práctica y desarrollar un sistema arbitral sobre la base de las decisiones de sus tribunales y árbitros, cuando en forma semejante a dichos sistemas, las partes voluntariamente someten a su resolución sus controversias y aquellas no son esencialmente confidenciales? Evidentemente no existe, según se ha demostrado impedimento alguno.

Es igualmente fundamental que un Instituto Especializado en Arbitraje, pueda tomar como inspiración la labor de la Cámara de Comercio Internacional, a fin de que consolide los laudos emitidos bajo las consideraciones expuestas en el presente trabajo y sea quien comunique periódicamente al público las decisiones resueltas en arbitraje, así como la elaboración de un compendio periódico de fallos, denotando fundamentalmente sus rationes decidendi para lo cual será fundamental que los diversos centros de arbitraje o los tribunales ad-hoc, actúen coordinación directa con dicho Instituto, a fin de remitirle la materia prima (laudos) y a su vez, recibir el producto (reportes de jurisprudencia arbitral). Nada favorecería más al arbitraje y a su posible jurisprudencia para el sistema arbitral ecuatoriano.

El objetivo del presente artículo ha sido demostrar la viabilidad del stare decisis en el arbitraje nacional ecuatoriano, entre puntos conciliables respecto de los diversos sistemas que han sido analizados, para concluir definitivamente que aquello que impide su viabilidad se resume en una sola palabra: nada. 
